\title{
Resonance Mitigation and Performance Improvement in Distributed Generation based LCL Filtered Grid Connected Inverters
}

\author{
Danish Khan ${ }^{1}$, Muhammad Mansoor Khan ${ }^{2}$, Yaqoob $\mathrm{Ali}^{3}$, Abdar $\mathrm{Ali}^{4}$, Imad Hussain ${ }^{5}$ \\ Department of Electrical Engineering \\ School of Electronic Information and Electrical Engineering \\ Shanghai Jaio Tong University \\ Shanghai, China
}

\begin{abstract}
Resonance turns into a growing issue of paramount importance for stable operation of LCL filtered grid-connected inverters. Active damping algorithms are widely adopted to restrain the resonance peak associated with $L C L$ filters. The focus of this paper is to develop an improved active damping solution based on filter capacitor current for better control performance of three-phase LCL grid-connected inverters. In the proposed solution, an improved compensator is included across the LCL filter system and capacitor current feedback. A damping loop is implemented with the proposed combination, which is further feedback at a reference voltage point of the three-phase inverter to damp the aroused resonance peak. The substantial features of the proposed configuration are wide damping range of resonance frequency and high control bandwidth, which results in faster dynamic response in comparison with conventional capacitor current proportionally feedback. Moreover, the stability of current loop is examined in detail by implementing the proposed damping method under the filter parametric variations. Finally, the efficacy of the proposed method is validated by illustrating the outcomes based on steady state and transient responses through simulations and experimental results of the laboratory prototype.
\end{abstract}

Keywords-LCL filter; high pass filter; grid connected inverters (GCI); stability analysis; robustness; SPWM technique; D-space

\section{BACKGROUND}

In recent years, growing concerns associated with climate change and increase in energy demand require new opportunities in the power sector[1]. Power quality issues along with stability issues of distribution Systems are becoming more significant with massive penetrations of Renewable Energy Resources. To build sustainable power systems for providing clean and renewable energy, low voltage power distribution system are frequently integrated with distributed generation units including wind power, photovoltaic power, and battery storage systems[2]. The mandatory and controlled active and reactive powers are injected through interfacing inverters known as pulse width modulated voltage source inverters [3].

Grid connected inverters have a considerable role in injecting power with high quality into power grids and utilized as an interface among the grid and renewable energy resource[4]. A filter is required to inject high quality power and to reduce high frequency harmonics produced due to pulse width modulation. The filter can be formed as either one inductor or two inductors with one capacitor LCL[5]. Among several available filters, LCL filter have drawn more attention due to enhance capability of current harmonics attenuation with lower value of inductance as compared to $\mathrm{L}$ and $\mathrm{LC}$ filters[6]. Furthermore, the grid side inductor in LCL filter limit the inrush current of capacitor and increase the robustness of inverter under grid impedance variation[5]. However, the presence of resonance phenomenon in LCL filter creates stability issues in control structure of the converter. The stability concern is raised due to high current gain produced by zero impedance at particular frequency that is called resonance frequency[7]. To prevent the instability issues in power grids produced by resonance effect, an appropriate damping approach is essential[8].

In general, for LCL filtered grid connected inverters, resonance suppression is achieved by employing active and passive damping approaches[9]. Passive damping approach is implemented by adding a passive component like inductor, resistor or both with the filter component. However, more power losses and reduced filter capability to suppress harmonics are the significant barriers of this approach[10]. Active damping approach has no damping losses by altering the control structure of an inverter [11]. However, the filter parameters variation and grid impedance may influenced the damping effectiveness of damping loop[12].

\section{INTRODUCTION}

Active damping can be implemented in different ways based on number of control loops to effectually handle the aforementioned problems. In active damping methods, depending on single control loop, damping of filter resonance is obtained without any further measurements[13]. Methods based on such approach are sensor less methods, grid current feedback and notched-filter based methods[13][14][15]. Generally, these methods have minimum robustness during parameter uncertainty and weak grid conditions [16].

In multi-loop active damping methods, additional measures are needed[9]. Filter capacitor voltage, capacitor current feedback and weighted average current control methods are associated with multi-loop active damping methods[17][18][19]. The robustness of these methods tends 
to be improved for filter parameter, and grid inductance variation is compared with single loop techniques.

Capacitor current feedback technique is mainly adopted in the literature due its simple operation, higher current quality, and damping effectiveness. The method is implemented with capacitor current is feedback through a coefficient for improved dynamics[20]. Furthermore, the stability features for this method are enhanced and the region of damping is extended by presenting a high pass filter and band pass filter in current control loop along with capacitor current[21][22]. These methods show reasonable effect of resonance damping; however, bandwidth is limited in case of grid impedance variation.

The focus of this paper is to introduce an alternative capacitor current method, which modify the damping loop with simple compensator adjustments in transfer function for capacitor current feedback damping method. The resonance peak is damped by further applying the capacitor feedback current across the LCL filter at a reference voltage. A modified controlled structure is demonstrated to improve the aforementioned issues. The proposed method presents better control performance of the system along with improvements in effective harmonic compensation region and control bandwidth of the system in comparison with the capacitor current active damping approaches method. Better robustness and faster dynamic response of the system even under week grid condition are substantial benefits of the proposed configuration.

The remainder of the paper is arranged as follows: Sections III explains the design of a typical three-phase system. Theoretical study of control and design of proposed compensator are presented in Section IV. Damping and comparative study analysis is examined in Section V. The simulation and prototype outcomes are illustrated in Section VI. Concluding comments are designated in Section VII.

\section{SySTEM DESCRIPTION AND DESIGN PARAMETERS}

A three-phase grid connected inverter system is presented in Fig. 1 and design parameters of the system are described in Table I. The inverter system is comprised of four main parts including conversion unit, power grid, filter unit, and inverter control. The assumed Constant DC-link bus voltage is supplied at the input of three-phase voltage source inverter, which is connected with the grid through LCL filter. The filter contains inverter side inductor $\mathrm{L}_{\mathrm{i}}$, grid side inductor $\mathrm{L}_{\mathrm{g}}$ and filter capacitor $C_{f}$. The filter capacitors are connected in delta. The resonance frequency of the LCL filter is given in equation (1).

$f_{\text {res }}=\frac{1}{2 \pi} \sqrt{\frac{L_{i}+L_{g}}{L_{i} L_{g} C_{f}}}$

Control structure is employed to ensure the significant objectives, which includes high quality of injected current without resonance component and unity power factor. The control structure contains current control loop and inner damping loop that ensures good steady-state and transient performance of the system. The current control loop is implemented by measuring the grid current $I_{g}$, which is transferred into stationary reference frame by using the abc$\alpha \beta$ module and compared with the reference grid current $\mathrm{I}_{\mathrm{g}}{ }_{\mathrm{g}}$. The reference grid current $\mathrm{I}_{\mathrm{g}}^{*}$ is obtained by measuring the angle of voltage at common coupling point $\mathrm{v}_{\mathrm{pcc}}$ using phase lock loop (PLL). Proportional Resonant (PR) controller $\mathrm{G}_{\mathrm{pr}}$ is used to regulate the error signal. The output of $G_{p r}$ controller produces a reference value for the inner damping loop.

The inner damping loop is implemented by measuring the filter capacitor current $I_{c}$, which is transferred into stationary reference frame by using the abc- $\alpha \beta$ module and compared with the reference current $\mathrm{I}_{\mathrm{c}}^{*}$. The reference capacitor current is achieved when the output of proportional $\mathrm{P}$ controller is feedback through a compensator in order to damp the resonance peak. This configuration is known as parallel feedforward compensation. Furthermore, the output of inner damping loop is transferred into sinusoidal signal by using $\alpha \beta$-abc module in order to produce a modulating signal for the inverter.

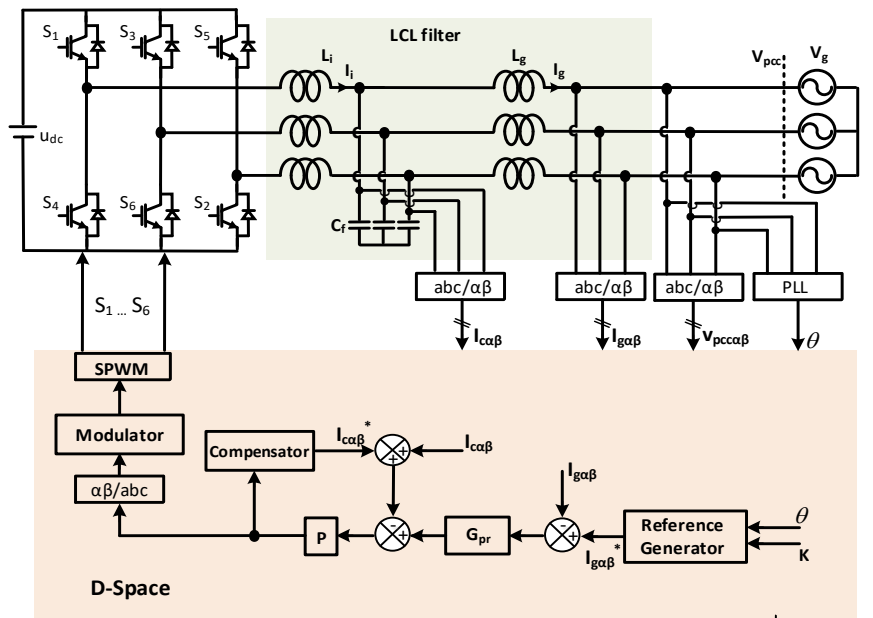

Fig. 1. Three-Phase LCL Filtered Grid Connected Voltage Source Inverter with Proposed Damping Loop.

TABLE. I. GRID PARAMETERS

\begin{tabular}{|l|l|l|}
\hline Parameter & Symbol & Value \\
\hline Grid voltage & $\mathrm{V}_{\mathrm{g}}$ & $400 \mathrm{~V}$ \\
\hline DC-Bus voltage & $\mathrm{V}_{\mathrm{dc}}$ & $800 \mathrm{~V}$ \\
\hline Inverter-side inductor & $\mathrm{L}_{\mathrm{i}}$ & $3.6 \mathrm{mH}$ \\
\hline Grid side inductor & $\mathrm{L}_{\mathrm{g}}$ & $1 \mathrm{mH}$ \\
\hline Filter capacitor & $\mathrm{C}_{\mathrm{f}}$ & $4.7 \mathrm{uF}$ \\
\hline Line frequency & $f_{l}$ & $50 \mathrm{~Hz}$ \\
\hline Sampling freq. & $f_{s}$ & $10 \mathrm{kHz}$ \\
\hline Switching freq. & $f_{\mathrm{sw}}$ & $10 \mathrm{kHz}$ \\
\hline Resonance freq. & $f_{\mathrm{res}}$ & $2.6 \mathrm{kHz}$ \\
\hline
\end{tabular}




\section{CONTROL LOOPS DESIGN}

The linearized "Average Switching Model (ASM)" related to control structure of an inverter is given in Fig. 2 to design the current control loop and inner damping loop. In this model, the inverter switches are represented by its average value using a function over each carrier interval [23].

\section{A. Proposed Damping Loop Design}

The capacitor current feedback method used for active damping is initially proposed by Twining and Holmes[10]. In this method, the capacitor current is feedback through a coefficient $\mathrm{H}(\mathrm{s})$ with the output of current controller, which provides an additional damping in the closed loop.

In this paper, an alternative intuitive method is used to construct the damping loop known as Parallel Feed-forward Compensation (PFC). According to this technique, the damping compensator in feedback loop is visualized as a linear compensator across the plant to improve the stability characteristics, and the augmented plant output is feedback at the current controller output [24][25][26]. The considered plant in this case is LCL filter between inverter output voltage and capacitor current and transfer function $\mathrm{K}(\mathrm{s})$ is added as a compensator is illustrated in Fig. 2(b). From stability point of view the diagram shown in Fig. 2(b) is similar to Fig. 2(c) where the damping loop is applied separately by visualizing the controller of Fig. 2(b) in two sections as shown in Fig. 2(c). The basic idea is to increase the output impedance of the grid-connected inverter at higher frequencies, thus further enhancing the suppression capability.

The compensator $\mathrm{K}(\mathrm{S})$ can have different expressions. Here a first order high pass filter is used as compensator, because it provides adequate damping to oscillations and show robust response against grid inductance variation with good transient response[21]. The transfer function of high pass filter is given in equation (2).

$K(s)=\frac{s k_{r c}(s)}{s+\omega_{r c}}$

Where, $\mathrm{k}_{\mathrm{rc}}$ and $\omega_{\mathrm{rc}}$ represent gain and cut-off-frequencies respectively. Intuitively speaking, the high pass filter in feedforward can be visualized as a resister and capacitor in parallel with the filter capacitor. With this alternative, the current through the filter capacitor $\mathrm{i}_{\mathrm{c}}$ is multiplied by a gain $k_{r c}$ to emulate the effect of a resistor in series with the filter capacitor. The cut off frequency $\Phi_{\mathrm{rc}}$ compensates the phase lag around the resonance frequency. At certain values of high pass filter parameters this configuration ensures a large stability margin, which is needed for accounting grid impedance variations. However, the high value of $\omega_{\mathrm{rc}}$ may also shift the gain crossover frequency over a wide range, leading into instability. Therefore, it is very important to select proper values of $k_{\mathrm{rc}}$ and $\omega_{\mathrm{rc}}$ to avoide instability. The compensator paramter are selected anaylitically from the stability plots as provided in Section IV.

For evaluating robustness and dynamic response subject to wider grid inductance variations, two transfer functions of the "plant" are necessary and derived accordingly. A linearized average switching model in ' $S$ ' domain of the proposed methodology is developed as shown in Fig. 3(a). Referring to Fig. 3(a), the transfer functions from the inverter output voltage $v_{\text {inv }}(s)$ to the grid current $\mathrm{I}_{\mathrm{g}}(\mathrm{s})$ and the capacitor current $\mathrm{I}_{\mathrm{c}}$ (s) can be derived as follows:

$$
\begin{aligned}
& G_{i g}(s)=\frac{I_{g}(s)}{V_{i n v}(s)}=\frac{1}{L_{i} L_{g} C} \cdot \frac{1}{s^{2}+\omega_{r e s}^{2}} \\
& G_{i c}(s)=\frac{I_{c}(s)}{V_{i n v}(s)}=\frac{1}{L_{i}} \cdot \frac{s^{2}}{s^{2}+\omega_{r e s}^{2}}
\end{aligned}
$$

From Fig. 3(a), the open damping loop with the proposed scheme can be calculated as

$$
I_{c}(s)=\frac{P Q(s)}{1+P(K(s)+Q(s))} \mathrm{I}_{c}^{*}
$$

Where the $\mathrm{Q}(\mathrm{s})=\mathrm{F}(\mathrm{s}) \cdot \mathrm{R}(\mathrm{s})$

$$
F(s)=\frac{G_{i n v}}{L_{i} C s^{2}+1}, R(s)=\frac{L_{i} C s^{2}+1}{C L_{i} L_{g} s^{3}+\left(L_{i}+L_{g}\right) s}
$$

\section{B. Current Control Loop Design}

The control parameters are sinusoidal; therefore, PR controller is used.The PR controller removes the steady state error and results in low-settling and rise time around the line frequency. Moreover, it is easer to implement and requires less work for signal processing. Equation (6) shows transfer function of an ideal PR controller.

$G_{P R}=K_{p}+\frac{2 K_{r} s}{s^{2}+\omega_{l}^{2}} \quad\left(\omega_{l}=2 \pi f_{l}\right)$

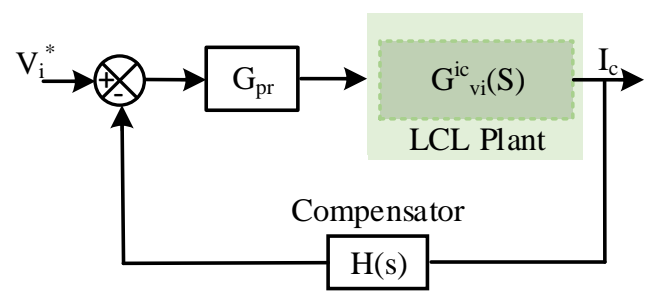

(a)

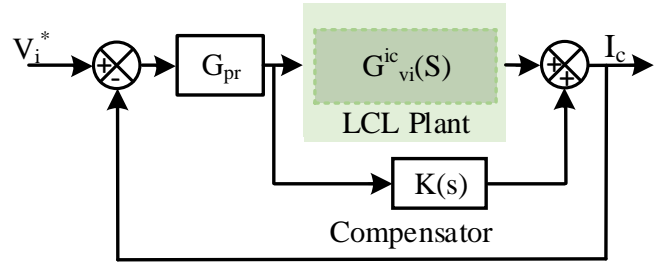

(b)

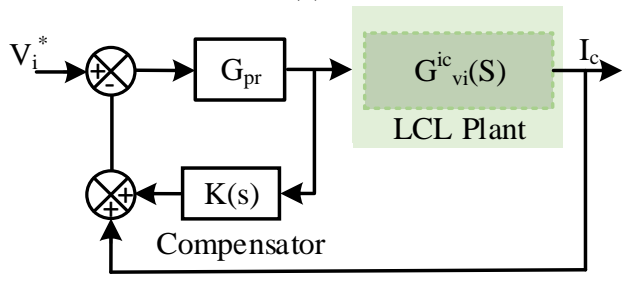

(c)

Fig. 2. Active Damping with (a) Proportional CCF Method (b) Parallel Feed-forward Configuration (c) Equivalent Control. 


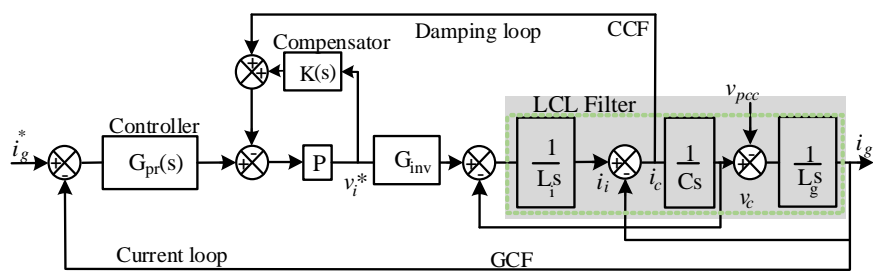

(a)

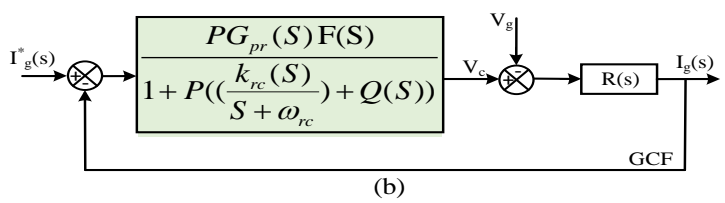

Fig. 3. (a) ASM Model of Proposed Method (b) Simplified Control Diagram.

Where $\omega_{l}, K_{p}$ and $K_{r}$ are resonant frequency, proportional gain and resonant gain, respectively. Quasi-PR (Q-PR) controller is an developed form of PR controller, which is implemented because of better harmonics attenuation capability along with less severity to resonance frequency. QPR controller transfer function is shown in equation (7), where the variation in fundamental frequency is compensated with the bandwidth of resonant term $\omega_{\mathrm{PR}}$

$G_{P R}=K_{p}+\frac{2 K_{r} \omega_{P R} s}{s^{2}+2 \omega_{P R} s+\omega_{l}^{2}}$

Using Mason's rule, the average switching model model shown in Fig. 3(a) is simplified to Fig. 3(b) and injected grid current $I_{g}$ is calculated. This current is equal to the sum of injected current by voltage $V_{g}$ and reference grid current $I^{*}{ }_{g}$ given in equations (8).

$\left.\begin{array}{l}I_{g}(s)=\frac{P G_{p r}(s) \cdot \mathrm{Q}(\mathrm{s})}{1+P\left[\mathrm{~K}(s)+Q(s)\left(1+G_{p r}\right)\right]} I_{g}^{*}(s)- \\ \frac{\mathrm{R}(s) \cdot[1+P(\mathrm{~K}(\mathrm{~s})+Q(s))]}{1+P\left[\mathrm{~K}(\mathrm{~s})+Q(s)\left(1+G_{p r}\right)\right]} v_{g}(s)\end{array}\right\}$

Equations (5) and (8) show that the damping attributes of miserable or non -minimum phase system can be enhanced with suitable values of $\mathrm{k}_{\mathrm{rc}}$ and $\omega_{\mathrm{rc}}$, which is discussed in this paper.

\section{DESIGN AND COMPARATIVE STUDY}

This section presents significant aspect of compensator parameter limits and comparative study of suggested method with conventional capacitor current feedback method. Furthermore, the stability performance of current control loop is analyzed with filter parameter variation. The design parameters are given in Table I.

\section{A. Compensator Parameters Limits}

The effects of gain and cut-off frequencies of high pass filter are illustrated in Fig. 4, where three scenarios are considered, in the $1^{\text {st }}$ case, the value of $\omega_{\text {rc }}$ is considered smaller than $\omega_{\mathrm{s}}$ (angular sampling frequency), while in the $2^{\text {nd }}$ and $3^{\text {rd }}$ case, the value is much higher than $\oplus_{s}$. To achieve similar magnitude in $\mathrm{db}$ and damping performance for all the cases, the damping $\mathrm{k}_{\mathrm{rc}}$ need to be much higher for larger $\omega_{\mathrm{rc}}$ and hence larger phase lag around the resonance frequency as shown in Fig. 4(b) and Fig. 4(c). For an acceptable system the gain and phase margin should be higher than $5 \mathrm{db}$ and 30 degree respectively. However, when the value of $\omega_{\text {rc }}$ increased, phase margin decreases dramatically below 30 degree as shown in Fig. 4(b) and Fig. 4(c). Therefore, to retain the system in acceptable margin a compromised range for the value of $\omega_{\mathrm{rc}}$ might be $0.2 \oplus \mathrm{s}<\omega \mathrm{rc}<0.5 \omega \mathrm{s}$, where the upper limit shows the Nyquist frequency that should not be exceeded because of noise amplification of high pass filter in noisy environment.

\section{B. Frequency Response}

The frequency response of proposed method is compared with conventional capacitor current feedback method as shown in Fig. 5. From the figure, it can be observed that in each case the resonance peak is damped effectively because the gain margin is very close to each other. The gain margin curve also shows much higher bandwidth for proposed technique, which ensures faster dynamic response for the suggested method. Moreover, the higher phase margin of proposed technique results in better delay response of the system. The phase margin curve also indicates high compensation capability of delay for proposed method with high control bandwidth. The values for the proposed scheme are derived through methods used in[12][21][27][28][29]. Moreover, the values used for conventional capacitor current feedback are those which offer best performance for this technique.

In Fig. 5(b) the frequency response of proposed and conventional CCF methods are compared for resonance frequency less than $f_{s} / 6$. The filter capacitance $C$ value is increased from its nominal value of $4.7 \mu \mathrm{F}$ to $22.5 \mu \mathrm{F}$ to shift the resonance below $\mathrm{f}_{\mathrm{s}} / 6$. From the figure it can be observed that the conventional capacitor current feedback method fail to damp the aroused resonance peak and the system is unstable. However, the proposed method damps the resonance peak with high phase margin. The proposed method maintains the stability of the system with wide range of resonance frequency.

\section{Robustness Evaluation}

The stability performance of current control loop is analyzed with filter parameter variation in Fig. 6(a), (b) and (c). When the inverter side inductor $\mathrm{L}_{\mathrm{i}}$ varies $50 \%$ above and below its nominal value, the system remains stable as shown in Fig. 6(a). In this case, the open loop is stable and the phase margin is above 50 degree and the gain margin is above $5 \mathrm{db}$. The system robustness and dynamic response reduces slightly for the lower value of $\mathrm{L}_{\mathrm{i}}$ but remain in acceptable margin. On the other side, for high value of $\mathrm{L}_{\mathrm{i}}$, the dynamic response is still higher and gain margin remain in acceptable region. Similar changes in grid side inductor $\mathrm{L}_{\mathrm{g}}$ are considered, which results in higher deviation in resonance frequency even the resonance frequency fall below $1 / 6^{\text {th }}$ of the sampling frequency $f_{s}$ as shown in Fig. 6(b). However, it shows greater phase margin and almost similar robustness as compared with variation in $\mathrm{L}_{\mathrm{i}}$. The current control loop is stable in both the cases. In Fig. 6(c), stability characteristics are observed under variation in filter capacitor; the overall result shows better phase margin with acceptable gain margin. The results shown in these graphs illustrate that proposed method is more robust to variation in resonance frequencies and can damp wide range of resonance frequencies with high phase margin. 

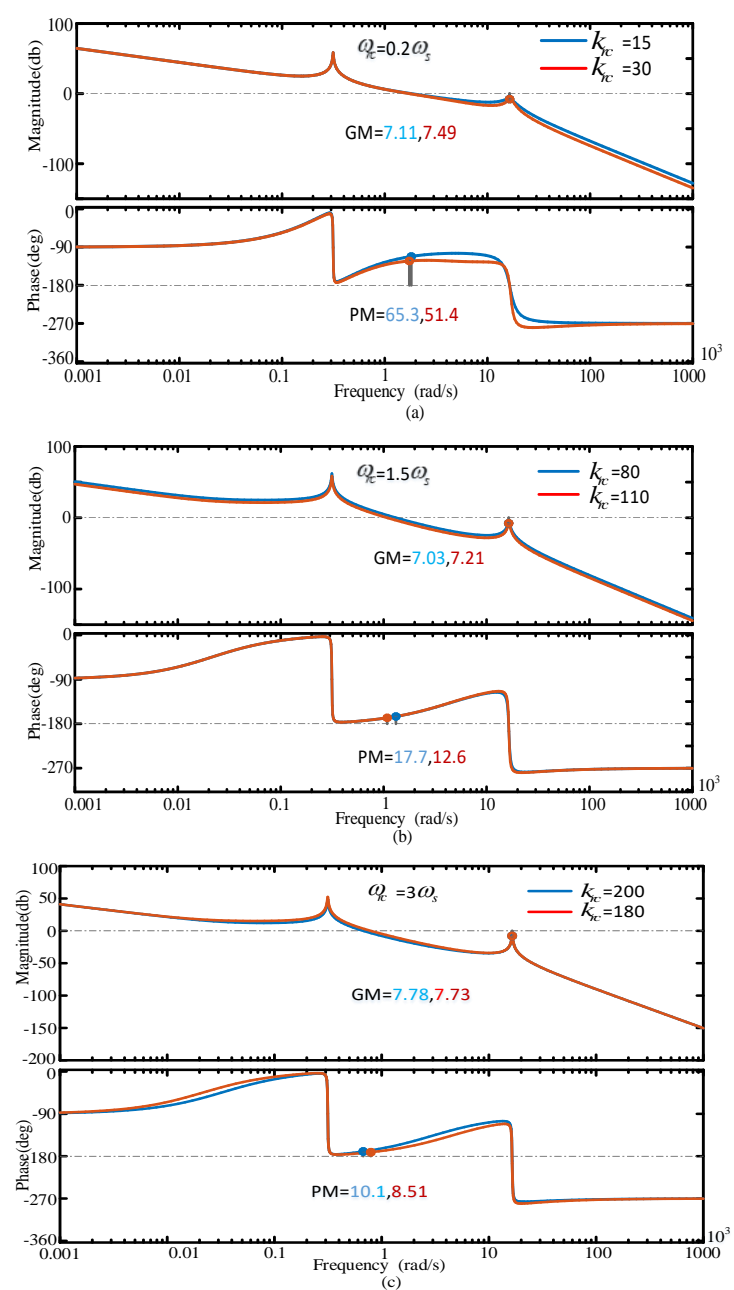

Fig. 4. Effect of (a) Low and (b and c) High Cutoff Frequencies Around LCL Resonance Frequency.
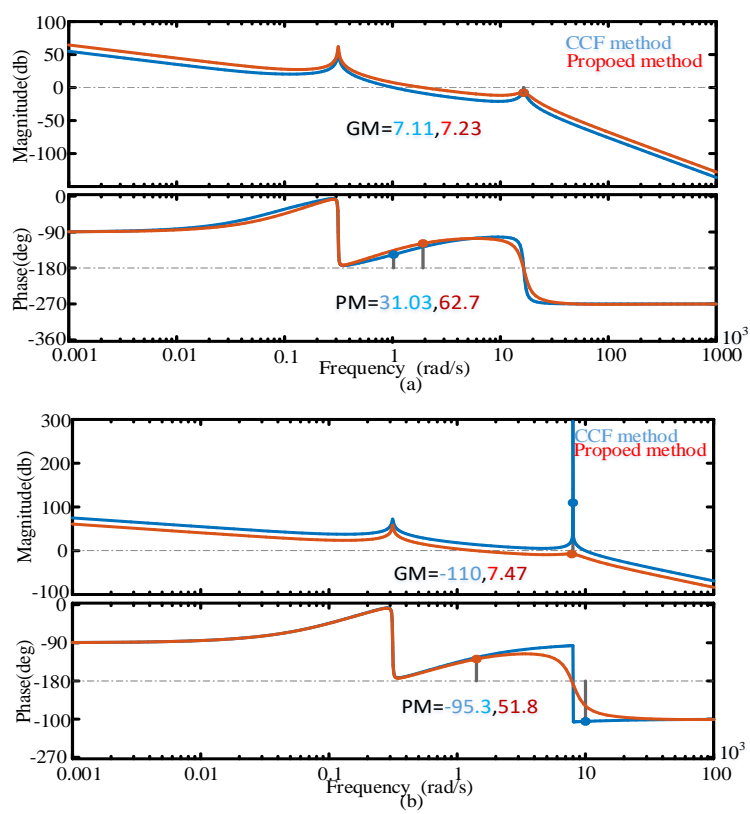

Fig. 5. Comparison of Proposed Method with Conventional CCF, and AD with PFC using Coefficient Gain.
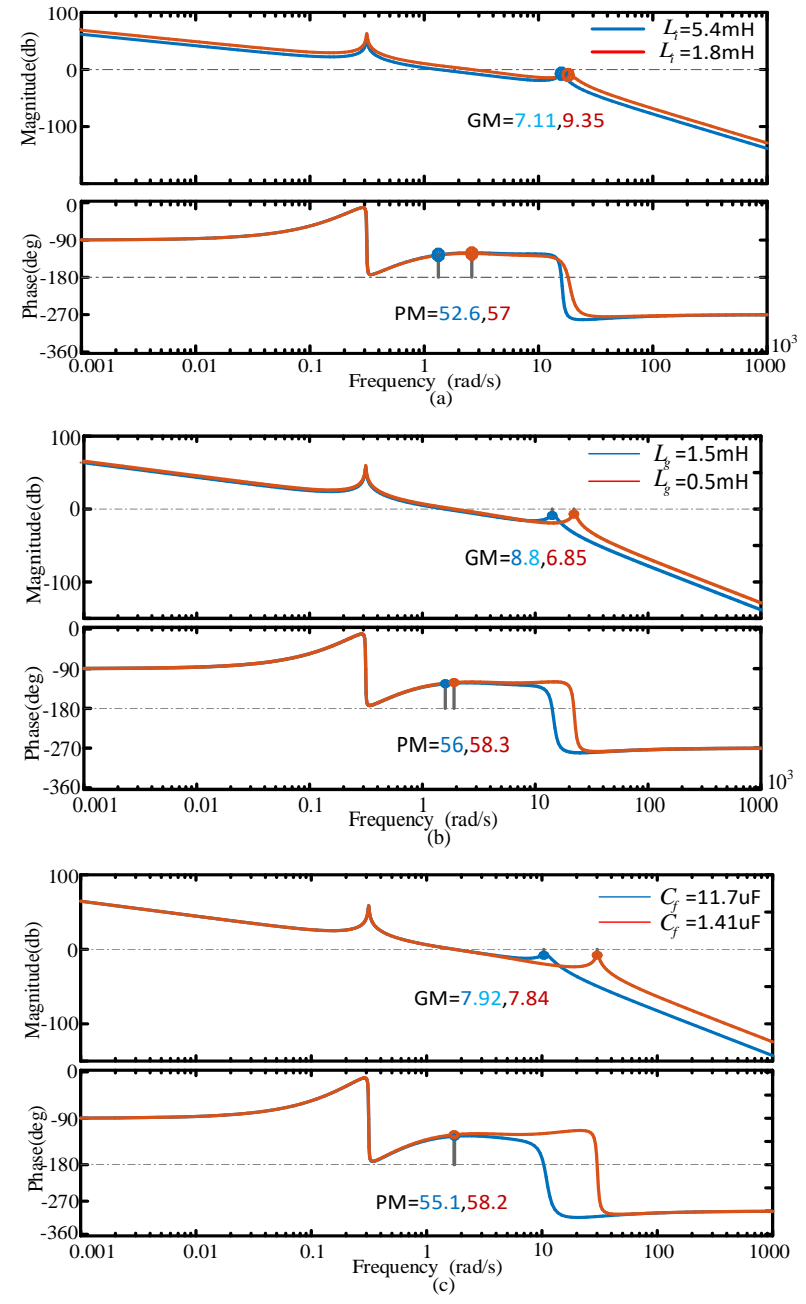

Fig. 6. Bode Plot under Filter Parameter Variation (a) $\mathrm{Li}+50 \%,-50 \%$ (b) $\mathrm{Lg}+50 \%,-50 \%$ (c) $\mathrm{C}+150 \%,-70 \%$.

\section{SimULATION AND EXPERIMENT RESUlTS}

To verify the effectiveness of proposed technique, a model of three-phase Grid-connected LCL filter is developed in MATLAB/Simulink environment. SPWM technique is used for gate signal generation. The design parameters of the system are described in Table I.

The steady-state injected current $I_{g}$ and voltage $V_{p c c}$ in phase A are shown in Fig. 7(a), Fig. 8(a) and Fig. 9(a) verifying the unity power factor operation. However, without the implementation of damping loop, the overall THD is $24.78 \%$ of the fundamental frequency where the contribution of resonance frequency region is highest as shown in Fig. 7(b). When conventional capacitor current feedback and proposed damping loop are applied, the overall THD is reduced to $6.39 \%$ and $3.28 \%$ respectively for the injected current, and the resonance peak is damped effectively as shown in Fig. 8(b) and Fig. 9(b). When damping is applied, half of the switching frequency region shows major contribution in the THD. However, with the proposed damping method the percentage is less than $5 \%$, which is acceptable because the grid standards allow THD of less than $5 \%$ of fundamental frequency for stable operation. 

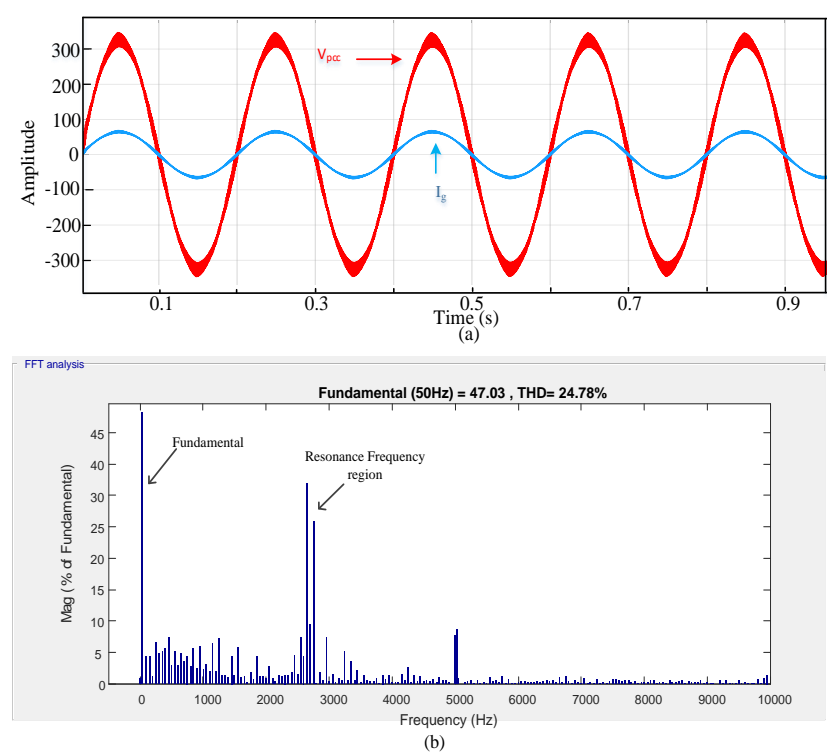

Fig. 7. Current Control Loop Response when no Damping Loop is Employed(a) $I_{g}$ and $v_{p c c}$ in Phase-A (b) Harmonic Spectrum of Igin Phase-A.
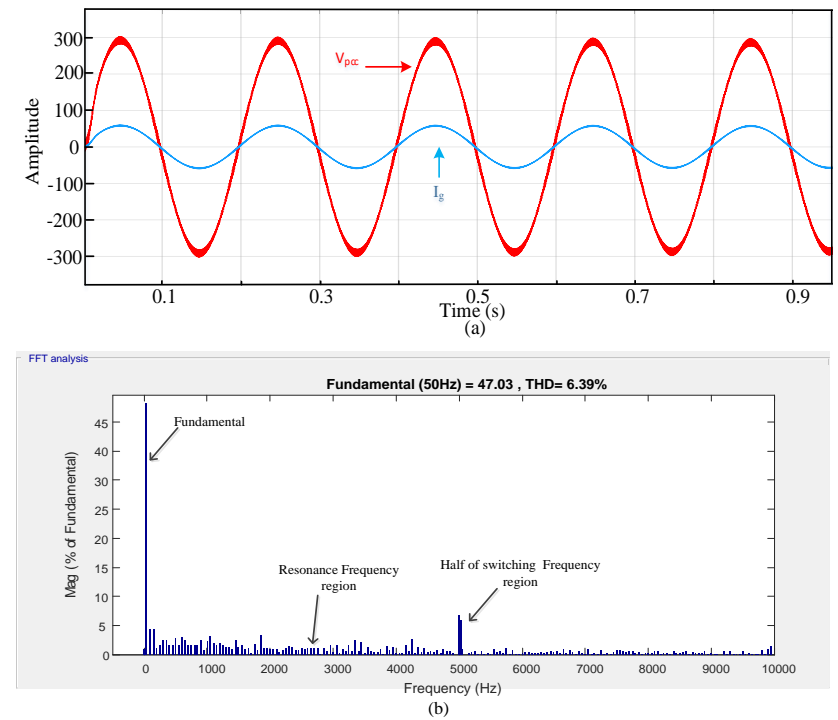

Fig. 8. Current Control Loop Response when CCF Damping Loop is Employed(a) $I_{g}$ and $v_{p c c}$ in Phase-A (b) Harmonic Spectrum of $I_{g}$ in Phase-A.

To illustrate the effect of resonance frequency shift, the filter capacitance $\mathrm{C}$ value is increased from its nominal value of $4.7 \mu \mathrm{F}$ to $22.5 \mu \mathrm{F}$. The stability and robustness of the system is examined for the resonance frequency of $1.2 \mathrm{kHz}$ and $\Phi_{\mathrm{rc}}=0.2 \Phi_{\mathrm{s}}$ as shown in Fig 10. The system does not exhibit inherent damping because in this case the resonance frequency is lower than $\mathrm{f}_{\mathrm{s}} / 6$. The figure illustrates that the conventional capacitor current feedback method fails to remove the resonance harmonics from the injected grid current and results in high THD and unstable system as shown in Fig. 10(a). However, with the proposed method the injected grid current tracks the reference current and also attenuate the resonance harmonics is shown in Fig. 10(b).

Fig. 11 verifies the better transient response of the system, when $50 \%$ reduction occurs in the reference load current, the measured current tracks the reference load current accurately.
The resultant overshoot is between $7-8 \%$, which is acceptable overshoot value, therefore, confirms the better transient response of the system.
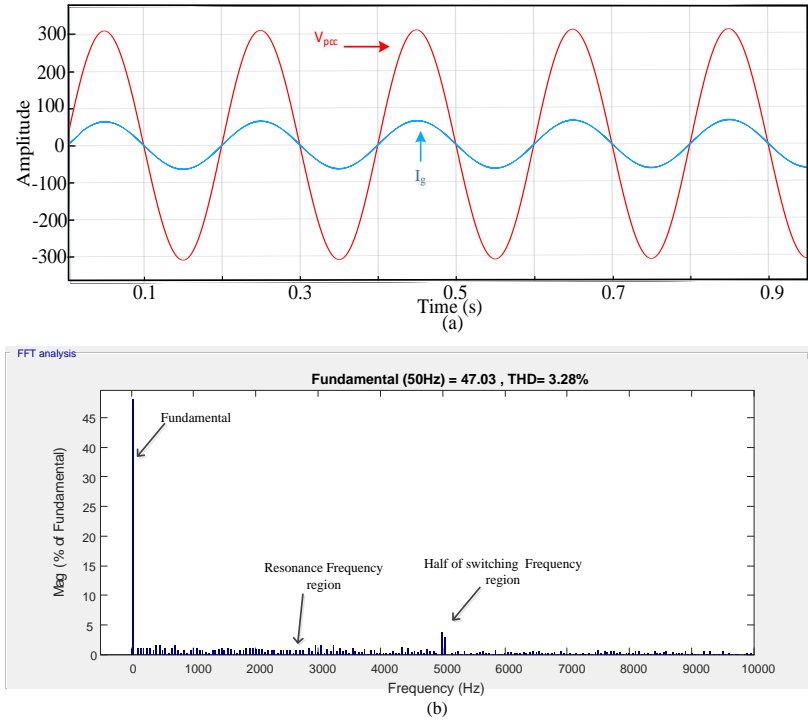

Fig. 9. Current Control Loop Response with Proposed Damping Loop (a) $I_{g}$ and $v_{p c c}$ in Phase-A (b) Harmonic Spectrum of $I_{g}$ in Phase-A.
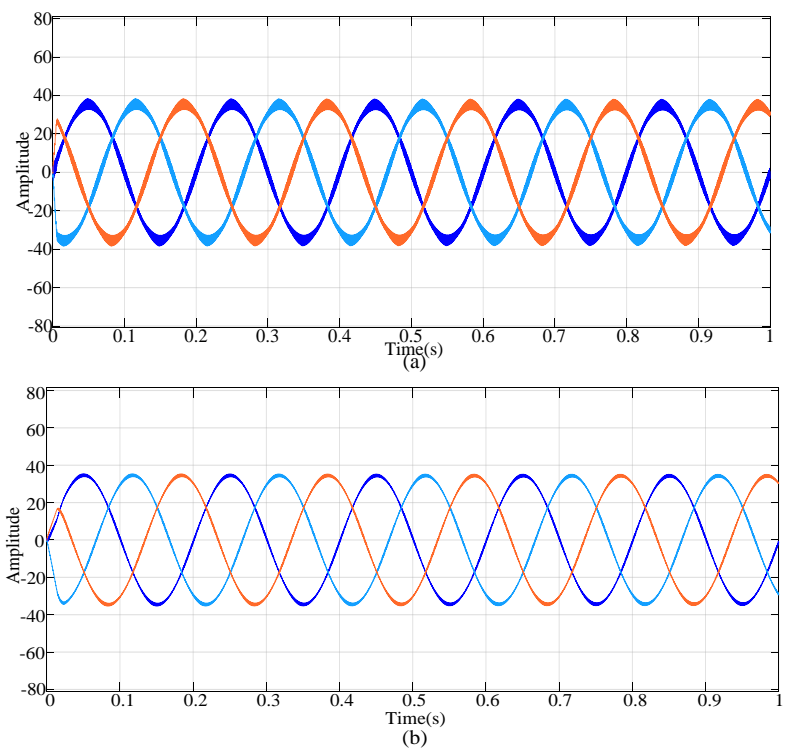

Fig. 10. Three Phase Injected Current behavior for Resonance Frequency Less than fs/6 (a) Conventional CCF (b) Proposed Method.

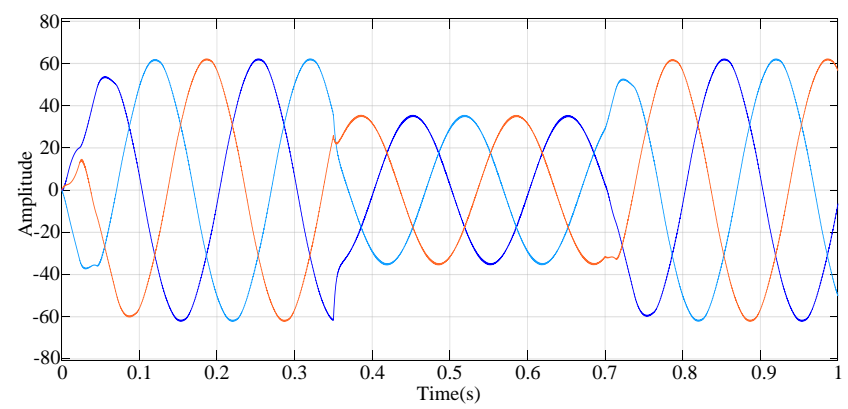

Fig. 11. Transient Response with Proposed Damping of Current Control Loop after Change in Reference Current. 


\section{A. Hardware Setup}

A $1 \mathrm{~kW}$ experimental setup of inverter is used to evaluate the control dynamic response and harmonic attenuation capability of the proposed method. The experimental test bench consists of an inverter with constant DC power source and LCL filter connected with grid is shown in Fig. 12. The overall control strategy, presented in Fig. 1, including the proposed resonance damping is implemented on D-Space DS1006 control board based on parameter shown in Table I.

Different performances are observed for damping strategy in the presence of grid voltage harmonics. The control board link the inverter and MATLAB simulated model for real-time operation. The control board or PWM board generates sinusoidal plus-width modulation signal for the switching devices (IGBTs) of the inverter with the accomplishment of PR controller in synchronous reference frame. The sample or sensor board is used for the measurement of DC bus voltage, three-phase injected grid currents and voltages at common coupling point. The transferred power to grid is $1 \mathrm{~kW}$ via three-phase inverter with $10 \mathrm{kHz}$ switching frequency.

The steady-state response of the current loop is shown in Fig. 13(a), Fig. 14(a), Fig. 15(a). However, without the implementation of damping method, the overall THD is $16.31 \%$ of the fundamental frequency where the influence of resonance frequency region is the highest as shown in Fig. 13(b). When conventional capacitor current feedback and proposed damping loop are applied the overall THD is reduced to $5.512 \%$ and $2.91 \%$ respectively for the injected current, and the resonance peak is damped effectively as shown in Fig. 14(b) and Fig. 15(b). The three-phase grid injected currents with the proposed damping loop are shown in Fig. 16.

The conventional capacitor current feedback method fails to maintain the stability of the system at low resonance frequencies but with the proposed method the region can be enhanced. In this section, the system response is examined under resonance frequency less than 1/6th of the sampling frequency and $\omega_{\mathrm{rc}}=0.2 \omega_{\mathrm{s}}$ as shown in Fig. 18. The filter capacitor $c_{f}$ value is increased from $4.7 \mathrm{uF}$ to $22.5 \mathrm{uF}$ to demonstrate the effect of resonance frequency shift. The system does not exhibit damping in case of conventional capacitor current feedback as shown in Fig. 17(a). However, the system is stable with the proposed method and show evidence of damping as shown in Fig. 17(b).

To verify the better transient response of the proposed method, there is step change in reference current from 2 to $4 \mathrm{~A}$ as shown in Fig. 18(a). Unlike proportional capacitor current feedback method discussed in [9] [10] and [28], there is no transient spikes and the injected current tracks the reference current smoothly with least amount of transient resonance and oscillation. The Phase-A line current THD for one cycle after the step change with the proposed damping loop is shown in Fig. 18(b).

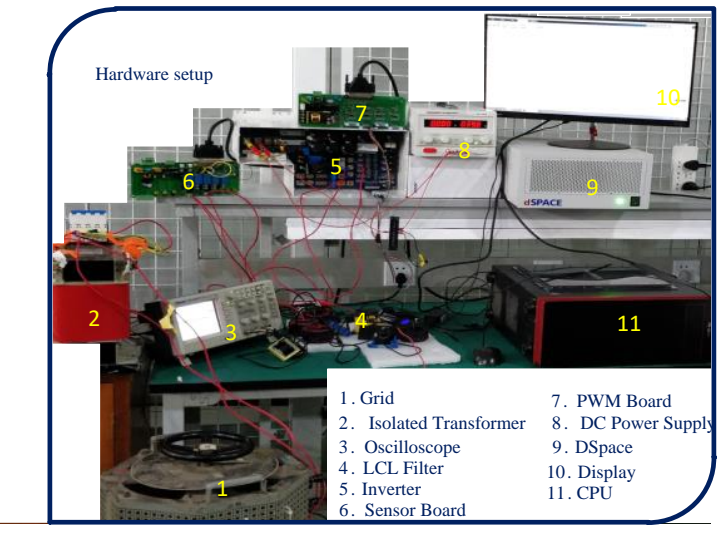

Fig. 12. Experimental Prototype of Three Phase Grid Connected Inverter using D-Space.

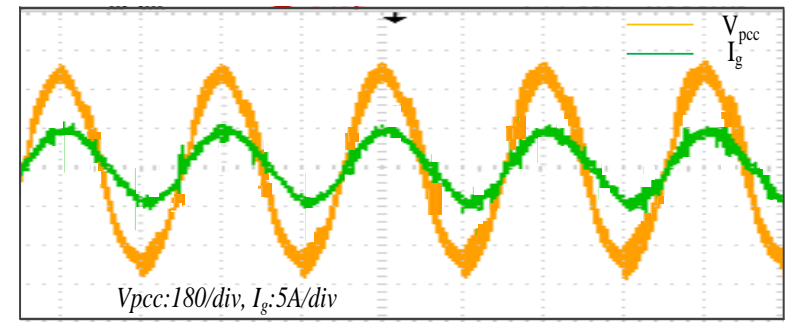

(a)

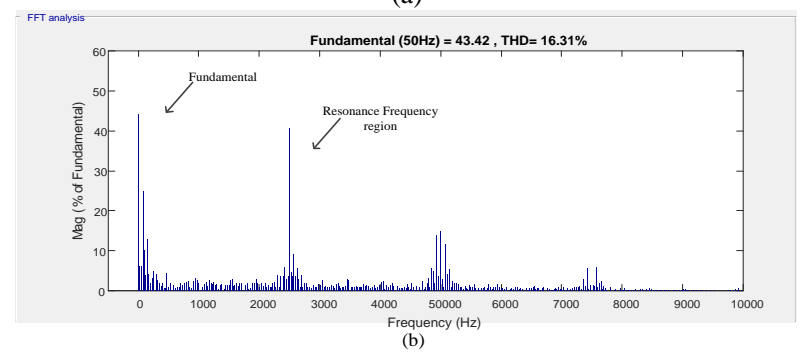

Fig. 13. Current Control Loop Response when no Damping Loop is Employed(a) $I_{g}$ and $v_{p c c}$ in Phase-A (b) Harmonic Spectrum of $I_{g}$ in Phase-A.
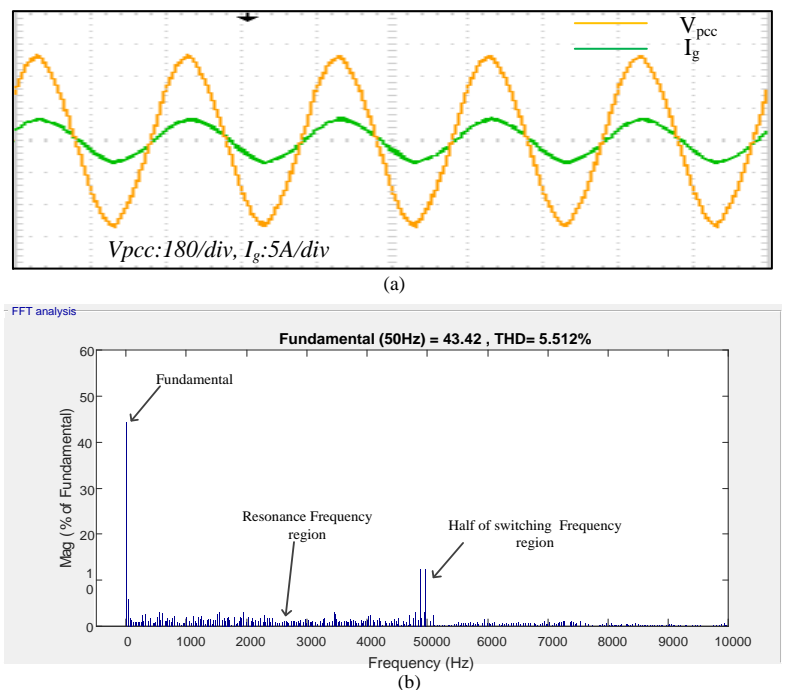

Fig. 14. Current Control Loop Response when CCF Damping Loop is Employed(a) $I_{g}$ and $v_{p c c}$ in Phase-A (b) Harmonic Spectrum of $I_{g}$ in Phase-A. 


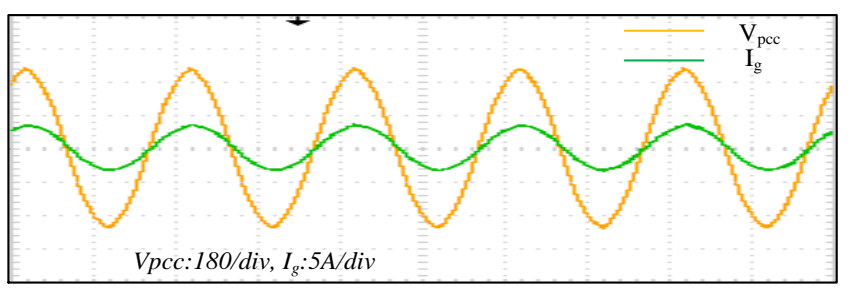

(a)

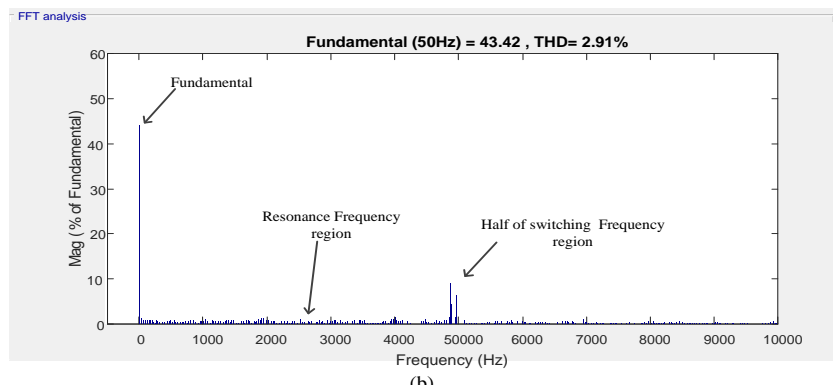

Fig. 15. Current Control Loop Response with Proposed Damping Loop (a) $I_{g}$ and $v_{p c c}$ in Phase-A (b) Harmonic Spectrum of $I_{g}$ in Phase-A.



Fig. 16. Three-Phase Inject Current with Proposed Damping Loop

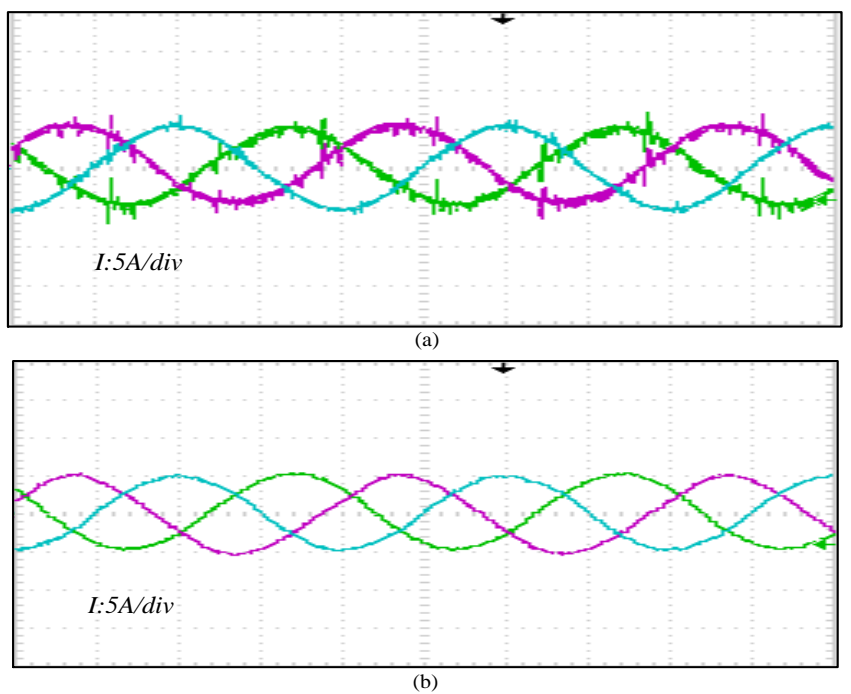

Fig. 17. Three Phase Injected Current behavior for Resonance Frequency Less than fs/6 (a) Conventional CCF (b) Proposed Method.

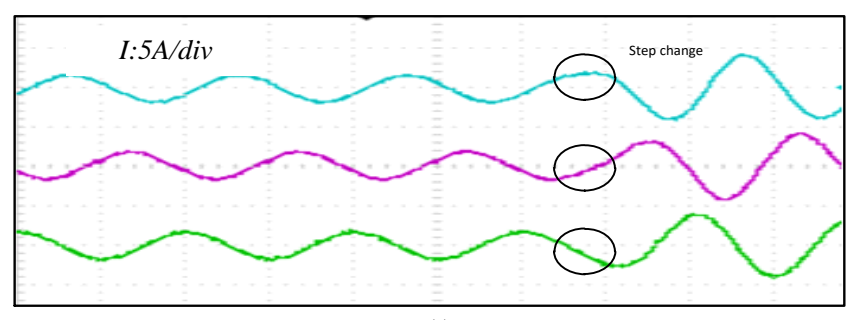

(a)

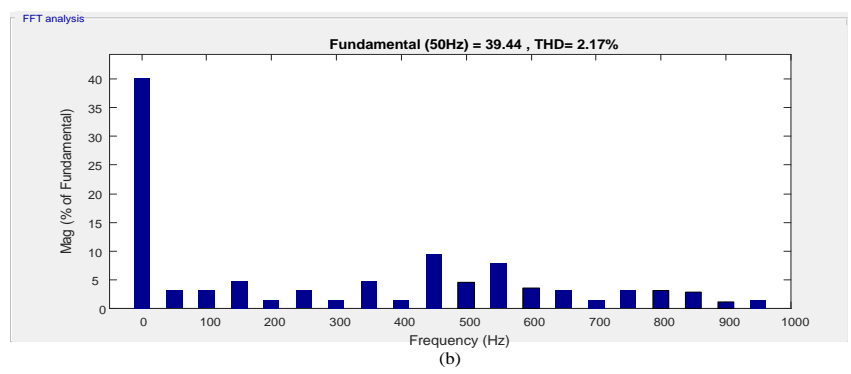

Fig. 18. (a) Transient Response and (b) Harmonic Spectrum, of Current Control Loop after Step Change in Reference Current.

\section{VII.CONCLUSION}

In this paper, active damping associated with three-phase grid connected LCL filter is explored with two different approaches. A new method is proposed, which is compared with the existing method to verify its efficacy. In the proposed strategy, a high pass filter is used as a compensator across the LCL filter to damp the arouse resonance peak. Based on proposed method, mathematical relation for grid injected current and capacitor damped current are derived. The proposed method gives faster dynamic response in comparison with conventional capacitor current feedback damping method. Moreover, the stability features with filter parameter variation illustrate that the proposed technique has potential to damp wide range of resonance frequencies as compared to the existing method. A case study of a $1 \mathrm{~kW}$ inverter is used to evaluate the control dynamic response and the harmonic attenuation capability. Different performances are observed for damping strategy in the presence of grid voltage harmonics. Finally, the simulation and experimental results validate the better dynamics response and damping effectiveness of the proposed methodology.

\section{REFERENCES}

[1] M. Huang, H. Li, W. Wu, and F. Blaabjerg, "Observer-Based Sliding Mode Control to Improve Stability of Three-Phase LCL-Filtered GridConnected VSIs," pp. 1-16, 2019.

[2] J. Park and K. Lee, "Performance Improvement for Reduction of Resonance in a Grid-Connected Inverter System Using an Improved DPWM Method," 2018.

[3] T. L. G. Converter, "Improved Capacitor Voltage Feedforward for," 2017

[4] A. Saim, A. Houari, J. M. Guerrero, A. Djerioui, M. Machmoum, and M. A. Ahmed, "Stability Analysis and Robust Damping of MultiResonances in Distributed Generation based Islanded Microgrids," IEEE Trans. Ind. Electron., vol. PP, no. c, p. 1, 2019.

[5] Y. W. Li, "Control and Resonance Damping of Voltage-Source and Current-Source Converters With LC Filters," vol. 56, no. 5, pp. 15111521, 2009.

[6] A. Akhavan, H. Reza, and J. M. Guerrero, "A comprehensive control system for multi-parallel grid-connected inverters with LCL fi lter in 
weak grid condition," Electr. Power Syst. Res., vol. 163, no. August 2017, pp. 288-300, 2018.

[7] Kang Zexin, Liu Chao, Sun Jiang, Ma Lin, You Haidong, and Jian Shuisheng, "Investigation on the Cladding Etched Single-Mode Fiber Acousto-Optic Tunable Filter and Its Axial Strain Characteristics," Acta Opt. Sin., vol. 33, no. 12, p. 1206003, 2013.

[8] X. Lu, K. Sun, and M. Liserre, "An Active Damping Method based on Biquad Digital Filter for Parallel Grid-interfacing Inverters with LCL Filters," pp. 392-397, 2014.

[9] C. C. Gomes, A. F. Cupertino, and H. A. Pereira, "Damping techniques for grid-connected voltage source converters based on LCL filter: An overview," Renew. Sustain. Energy Rev., vol. 81, no. April 2017, pp. 116-135, 2018.

[10] E. Twining, S. Member, and D. G. Holmes, "Grid Current Regulation of a Three-Phase Voltage Source Inverter With an LCL Input Filter," vol. 18, no. 3, pp. 888-895, 2003.

[11] X. Wang, X. Ruan, S. Member, S. Liu, and C. K. Tse, "Full Feedforward of Grid Voltage for Grid-Connected Inverter With LCL Filter to Suppress Current Distortion Due to Grid Voltage Harmonics," vol. 25 , no. 12, pp. 3119-3127, 2010.

[12] X. Renzhong, X. Lie, Z. Junjun, and D. Jie, "Design and Research on the LCL Filter in Three-Phase PV Grid-Connected Inverters," vol. 5, no. 3, pp. 3-6, 2013.

[13] J. Xu, B. Zhang, Q. Qian, X. Meng, and S. Xie, "Robust control and design based on impedance-based stability criterion for improving stability and harmonics rejection of inverters in weak grid," Conf. Proc. - IEEE Appl. Power Electron. Conf. Expo. - APEC, pp. 3619-3624, 2017.

[14] H. Athari, M. Niroomand, and M. Ataei, "Review and Classi fi cation of Control Systems in Grid-tied Inverters," Renew. Sustain. Energy Rev., vol. 72, no. February 2016, pp. 1167-1176, 2017.

[15] M. Malinowski and S. Bernet, "A Simple Voltage Sensorless Active Damping Scheme for Three-Phase PWM Converters With an LCL Filter," Ieee Trans. Ind. Electron., vol. 55, no. 4, pp. 1876-1880, 2008.

[16] S. Gulur, V. M. Iyer, and S. Bhattacharya, "Stationary reference frame based current control structure with improved disturbance rejection for grid connected converters," Conf. Proc. - IEEE Appl. Power Electron. Conf. Expo. - APEC, vol. 2018-March, pp. 1031-1035, 2018.

[17] W. Yao, Y. Yang, X. Zhang, and F. Blaabjerg, "Digital Notch Filter based Active Damping for LCL Filters," 2015 IEEE Appl. Power Electron. Conf. Expo., pp. 2399-2406, 2015.
[18] T. Nhan, A. Luo, and M. Li, "A simple and robust method for designing a multi-loop controller for three-phase VSI with an LCL-filter under uncertain system parameters," Electr. Power Syst. Res., vol. 117, pp. 94-103, 2014.

[19] J. He, S. Member, Y. W. Li, S. Member, D. Bosnjak, and B. Harris, "Investigation and Active Damping of Multiple Resonances in a Parallel-Inverter-Based Microgrid," IEEE Trans. Power Electron., vol. 28, no. 1, pp. 234-246, 2013.

[20] T. Liu, Z. Liu, J. Liu, Y. Tu, and Z. Liu, "An Improved CapacitorCurrent-Feedback Active Damping for LCL Resonance in GridConnected Inverters," 2017 IEEE 3rd Int. Futur. Energy Electron. Conf. ECCE Asia (IFEEC 2017 - ECCE Asia), pp. 2111-2116, 2017.

[21] X. Yan, J. Tang, W. Zhang, and Y. Zhang, "multi-objective optimization design for active damping lcl grid-connected filter."

[22] S. G. Parker, B. P. McGrath, and D. G. Holmes, "Regions of active damping control for LCL filters," IEEE Trans. Ind. Appl., vol. 50, no. 1, pp. 424-432, 2014

[23] X. Wang, F. Blaabjerg, and P. C. Loh, "Virtual RC Damping of LCL Filtered Voltage Source Harmonic Compensation," vol. 30, no. 9, pp. 4726-4737, 2015.

[24] M. T. Faiz, M. M. Khan, X. Jianming, S. Habib, and H. Tang, "Parallel feedforward compensation based active damping of LCL-type grid connected inverter," Proc. IEEE Int. Conf. Ind. Technol., vol. 2018Febru, pp. 788-793, 2018.

[25] Z. Iwai and I. Mizumoto, "Realization of simple adaptive control by using parallel feedforward compensator," Int. J. Control, vol. 59, no. 6, pp. 1543-1565, 1994.

[26] I. Bar-Kana, "Parallel feedforward and simplified adaptive control," Int. J. Adapt. Control Signal Process., vol. 1, no. 2, pp. 95-109, 1987.

[27] J. He, S. Member, Y. W. Li, and S. Member, "Generalized Closed-Loop Control Schemes with Embedded Virtual Impedances for Voltage Source Converters with LC or LCL Filters," vol. 27, no. 4, pp. 18501861, 2012.

[28] M. T. Faiz, M. M. Khan, X. Jianming, M. Ali, and M. A. Mumtaz, "Active Damping of Capacitor Current based on Parallel Feedforward Compensation of LCL Grid Connected Inverter," 2018 Int. Conf. Electr. Eng., pp. 1-6.

[29] A.Ali, M. Mansoor Khan, J. Yuning, Y. Ali, M. T. Faiz and J. Chuanwen,"ZVS/ZCS Vienna rectifier topology for high power applications," in IET Power Electronics, vol. 12, no. 5, pp. 1285-1294, 1 5 2019. doi: 10.1049/iet-pel.2018.5875. 